\title{
Launching the first postgraduate diploma in medical entomology and disease vector control in Pakistan
}

\author{
H.R. Rathor, ${ }^{1}$ A. Mnzava, ${ }^{2}$ K.M. Bile, ${ }^{3}$ A. Hafeez ${ }^{4}$ and S. Zaman ${ }^{5}$
}

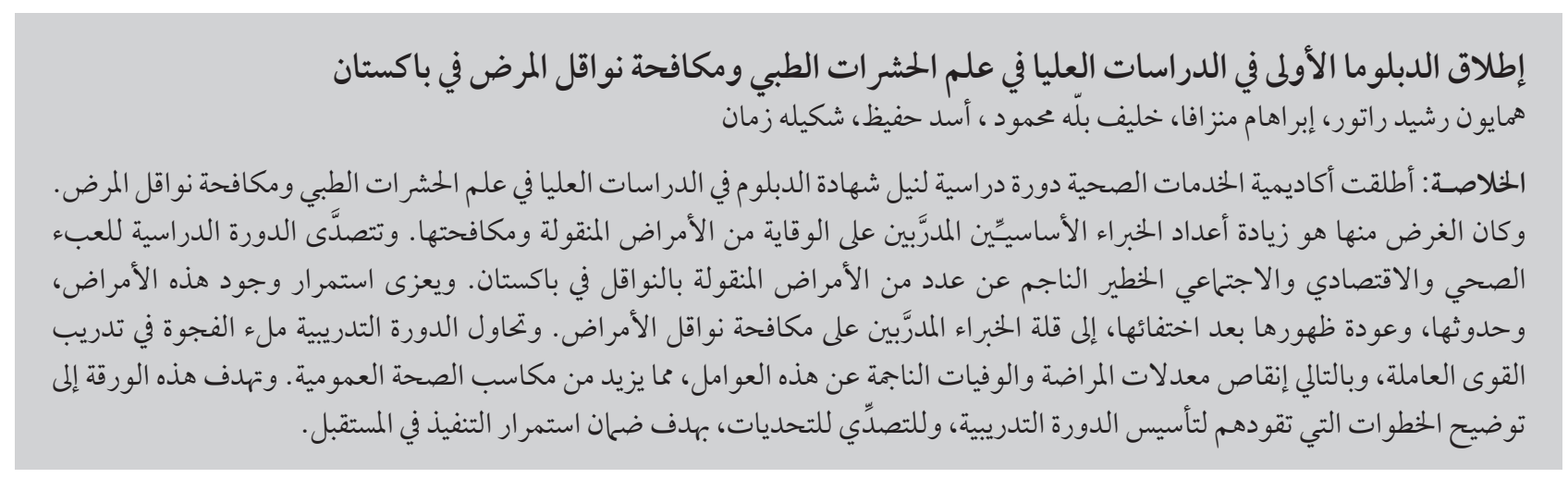

ABSTRACT The Health Services Academy has launched a 12-month postgraduate diploma course in medical entomology and disease vector control. The objective is to create a core of experts trained to prevent and control vector-borne diseases. The course is a response to the serious health and socioeconomic burden caused by a number of vector-borne diseases in Pakistan. The persistence, emergence and re-emergence of these diseases is mainly attributed to the scarcity of trained vector-control experts. The training course attempts to fill the gap in trained manpower and thus reduce the morbidity and mortality due to these diseases, resulting in incremental gains to public health. This paper aims to outline the steps taken to establish the course and the perceived challenges to be addressed in order to sustain its future implementation.

Lancement du premier diplôme postuniversitaire en entomologie médicale et lutte contre les vecteurs de maladies au Pakistan

RÉSUMÉ Les Health Services Academy [Académie des services de santé] ont lancé un diplôme postuniversitaire d'une durée de 12 mois dans le domaine de l'entomologie médicale et de la lutte contre les vecteurs de maladies, dans le but de constituer un noyau d'experts formés à la lutte contre les maladies à transmission vectorielle. Cette formation est une riposte à la lourde charge sanitaire et socioéconomique que représentent un certain nombre de maladies à transmission vectorielle au Pakistan. La persistance, l'émergence et la réapparition de ces maladies sont essentiellement attribuées au manque d'experts formés à la lutte contre les vecteurs de maladies. La formation vise à combler ce manque et à réduire ainsi la morbidité et la mortalité dues à ces maladies, entraînant de ce fait une amélioration croissante de la santé publique. Le but de cet article est de mettre l'accent sur les mesures prises pour mettre en place la formation et les défis à relever pour soutenir sa future mise en ouvre.

'Medical Entomology and Disease Vector Control, Health Services Academy, Islamabad, Pakistan (Correspondence to H. Rathor: hamayun_r@ hotmail.com).

${ }^{2}$ World Health Organization Regional Office for the Eastern Mediterranean, Cairo, Egypt.

${ }^{3}$ World Health Organization, Country Office, Islamabad, Pakistan.

${ }^{4}$ Health Services Academy, Islamabad, Pakistan.

IInstitute of Public Health, Lahore, Pakistan. 


\section{Introduction}

Vector-borne diseases, such as malaria, filariasis, leishmaniasis, schistosomiasis, onchocerciasis, dengue and other arboviruses, rodent-borne diseases, and a number of other diseases transmitted by insects, cause major public health problems and burden of diseases in countries of the World Health Organization's (WHO)'s Eastern Mediterranean Region, including Pakistan [1-6]. Resurgence and re-emergence of some of these diseases continues to take place in Member States [7]. In 2001, an estimated 14657000 disability-adjusted life years were lost in countries in the Region due to infections from the top 10 vector-borne diseases, accounting for $11 \%$ of the global burden in an area where only $8 \%$ of the global population lives $[8,9]$.

According to the annual report of the Directorate of Malaria Control, Islamabad, 2008, the incidence of Plasmodium falciparum has been increasing in Baluchistan, Sind, North-west Frontier Province (NWFP) and Federally Administered Tribal Area (FATA), causing serious health problems. Crimean-Congo haemorrhagic fever has been reported from many parts of Baluchistan, Sind and northern Punjab [10]. Cutaneous leishmaniasis of anthroponotic and zoonotic nature, earlier only found in NWFP, has become endemic and often causes outbreaks in all four provinces [11-14]. An outbreak of dengue fever was first reported from Karachi, Pakistan in 1994 [15] and since then various dengue outbreaks have been reported from different regions of Pakistan [16].

The control of vectors of dengue, malaria, leishmaniasis, etc, requires availability of medical entomologists and vector-control experts, not only to provide leadership but also to monitor and evaluate the impact of existing vector-control interventions. Therefore, capacity building in medical entomol- ogy and disease vector control must be a top priority for Pakistan.

In addition to the damage caused by the known endemic vector-borne diseases, the presence of vectors capable of transmitting other diseases which, although not yet reported from Pakistan, have caused outbreaks in neighbouring countries and pose as an emerging risk. An important example was an outbreak of plague in 1994 that caused serious alarm in India [17,18].

WHO warned the health authorities in Pakistan of the risks the country was facing due to the persistence, emergence and possible re-emergence of vectorborne diseases and the country's serious lack of trained medical entomologists and vector-control experts to prevent and control any adverse health impacts. To address this human resource gap, the Ministry of Health asked WHO to work with its Health Service Academy (HSA), Islamabad to review and finalize the syllabus for a postgraduate diploma course in medical entomology and vector control. This initiative was fully supported in the Region's 52nd Regional Committee meeting [19]. Through the joint collaborative programme, the blueprint of a medical entomology and disease vector control (MEDVC) course was designed for implementation of integrated vector management (IVM) as the most suitable strategic approach to reduce the burden of vectorborne diseases and reduce the critical gap in trained manpower to carry out indigenous applied research and vectorcontrol operations [20-23].

In view of the above, HSA, with the support of WHO and the United States Agency for International Development (USAID), launched a postgraduate diploma in MEDVC in September 1 2009. MEDVC is a remarkable innovation for capacity building in a neglected but essential preventive field of public health.

\section{Methods}

Information was gathered from existing technical documents to design a course curriculum that was unique to the needs of Pakistan. Such documents included an existing curriculum from the $\mathrm{WHO}$ Regional Office for the Eastern Mediterranean, WHO regional courses, and curricula for other courses currently offered at HSA. The biggest challenge was to align this course with the requirements of Quaid-e-Azam University, the diploma-awarding academic institution. Teaching consultancy and course approval processes were reviewed. Interviews with senior national and $\mathrm{WHO}$ experts were instrumental in evaluating the opportunities and challenges that would influence the sustainability of the course.

\section{Results}

Table 1 lists the diseases, their vectors, intermediate hosts and reservoirs found in Pakistan. Many of these vector-borne diseases are endemic; for others the vector epidemiology and environmental conduciveness pose the risk of disease resurgence, though cases have not yet been reported in Pakistan.

\section{Inception of the course}

In order to launch the MEDVC course, multisectoral discussions were held among the concerned national authorities and a plan of action was prepared. HSA agreed to take the initiative and launched the MEDVC course. The syllabus, designed jointly by the Regional Office and HAS, emphasized both the applied field aspects of disease vector control and indigenous research, to ensure the application of knowledge gained.

\section{Collaboration with Qaid-e- Azam University}

HSA collaborated with Qaid-e-Azam University, Islamabad, for the purpose 


\begin{tabular}{|c|c|c|c|c|}
\hline Disease & $\begin{array}{l}\text { Vector/intermediate hosts/ } \\
\text { reservoirs }\end{array}$ & Vector status & $\begin{array}{l}\text { Environment } \\
\text { (habitat) }\end{array}$ & Disease status \\
\hline Malaria & Anopheles spp. & Present & Favourable & Endemic \\
\hline Cutaneous leishmaniasis & Sand flies, rodents & Present & Favourable & Endemic \\
\hline Visceral leishmaniasis & Sand flies, dogs, cats & Present & Favourable & Endemic in north \\
\hline $\begin{array}{l}\text { Dengue and dengue haemorrhagic } \\
\text { fever }\end{array}$ & Aedes aegypti, A. albopictus & Present & Favourable & Endemic \\
\hline Crimean-Congo haemorrhagic fever & Ticks (cattle, sheep) & Present & Favourable & Endemic \\
\hline Yellow fever & A. aegypti & Present & Unknown & Not reported \\
\hline Japanese encephalitis & Culex tritaeniorhynchus & Present & Favourable & Not reported \\
\hline Filariasis & C. quinquefasciatus, Anopheles spp. & Present & Favourable & Reported \\
\hline Plague & Fleas, rodents & Present & Favourable & Not present \\
\hline Murine typhus & Fleas, Rattus spp. & Present & Favourable & Reported \\
\hline Salmonellas & Rattus spp. & Present & Favourable & Reported \\
\hline $\begin{array}{l}\text { Dysentery, diarrhoea, cholera, } \\
\text { typhoid, helminth infections, } \\
\text { trachoma, poliomyelitis }\end{array}$ & Housefly & Present & Favourable & Present \\
\hline Relapsing fever & Rattus spp., Acomys spp. & Present & Favourable & Reported \\
\hline Leptospirosis & Rattus spp., Mus spp. & Present & Unknown & Not reported \\
\hline Louse-borne typhus & Body louse & Present & Favourable & Reported in north \\
\hline House dust mite allergies & Dust mites & Present & Favourable & Reported \\
\hline Guinea worm (dracunculiasis) & Cyclops & Present & Eradicated 1996 & Not present \\
\hline $\begin{array}{l}\text { Haemorrhagic fever with renal } \\
\text { syndrome }\end{array}$ & Rodents & Present & Favourable & Not reported \\
\hline Onchocerciasis & Black fly (Simulium not reported) & Present & Unknown & Not reported \\
\hline
\end{tabular}

of awarding diplomas to students. A plan for collaborative teaching and evaluation, along with the syllabus, was approved by the academic council of the university. Consequently, the course was offered by Quaid-e-Azam University as a one-year programme to be administered by HSA.

Table 2 shows the course structure. There are two semesters, comprising of six modules in subspecialties in the field of vector biology and control and a three-month research dissertation. A brief description of the syllabus, duration and the credit hours allotted to each module are explained. The table also includes arrangements for local and international faculty in relation to each module of the syllabus. A total of 25 faculty were recruited: nine were from HSA, 11 were local visiting faculty from various universities and organizations in Pakistan, and the remainder were international visiting faculty members.

\section{Admission procedures}

As the course was expected to attract a large number of candidates from all over the country, an advertisement was placed in different national newspapers. The target was to admit 20 students. A total of 96 candidates applied, 70 of whom were shortlisted on the basis of qualifications and experience and further screened by a written test and interview. As detailed in the prospectus, due consideration was also given to other admission criteria such as age (maximum 30 years without experience or 45 years with experience), provincial quotas, English language, computer skills and no objection certificate requirement for those in service. A batch of 26 students was finally admitted to the first MEDVC programme. Of these 26 students, 13 held BSc degrees in agriculture (2), biology (2), bio-informatics (2), medical technology (5), pharmacy (1), microbiology (1), while 10 had MSc degrees in biochemistry (1), zoology (4), botany (1), microbiology (1), agriculture (1), and three had medical degrees. This clearly indicated that the course was of great interest to students from many diverse biomedical backgrounds. This diversity was considered useful, as it would help to promote multidiscipline interaction within the class and an environment of participatory learning.

By careful review of transcripts of their undergraduate studies and from the personal interviews that formed part of the admission process, it was determined that all students had a basic knowledge of biosciences from their undergraduate studies. The only weak area in the background of most students was a limited knowledge of basic 


\begin{tabular}{|c|c|c|c|}
\hline Module & $\begin{array}{l}\text { Duration } \\
\text { (months) }\end{array}$ & Credit hours & Faculty \\
\hline \multicolumn{4}{|l|}{ Module 1} \\
\hline $\begin{array}{l}\text { Medical entomology, disease and vectors and vector-borne } \\
\text { disease } \\
\text { Identification, classification, bionomics of vectors and } \\
\text { disease transmission mechanism and significance }\end{array}$ & 1 & 6 & HSA + local visiting faculty \\
\hline \multicolumn{4}{|l|}{ Module 2} \\
\hline $\begin{array}{l}\text { Epidemiological investigations and statistics } \\
\text { Epidemiological concepts, statistical principles and } \\
\text { methodology, principles and methodology of study design, } \\
\text { application of computers for vector and disease control }\end{array}$ & 1 & 6 & $\mathrm{HSA}+$ local visiting faculty \\
\hline \multicolumn{4}{|l|}{ Module 3} \\
\hline $\begin{array}{l}\text { Entomological investigations } \\
\text { Skills for sampling, monitoring, rearing, identification, } \\
\text { incrimination of disease vectors, intermediate host and } \\
\text { reservoirs }\end{array}$ & 1 & 6 & $\begin{array}{l}\mathrm{HSA}+\text { local visiting + } \\
\text { international faculty }\end{array}$ \\
\hline \multicolumn{4}{|l|}{ Module 4} \\
\hline $\begin{array}{l}\text { Vector control and management } \\
\text { Concepts and techniques for vector pest prevention and } \\
\text { control. Integrated vector management, safe use of } \\
\text { pesticides and insecticide-resistance management }\end{array}$ & 1 & 6 & $\begin{array}{l}\text { HSA + local visiting + } \\
\text { international faculty }\end{array}$ \\
\hline \multicolumn{4}{|l|}{ Module 5} \\
\hline $\begin{array}{l}\text { Principles of programme management: } \\
\text { Main principals and methodology of programme } \\
\text { management as related to vector control, especially } \\
\text { integrated vector management }\end{array}$ & 1 & 6 & HSA faculty \\
\hline \multicolumn{4}{|l|}{ Module 6} \\
\hline $\begin{array}{l}\text { Field training } \\
\text { Skills for field work and community empowering and } \\
\text { involvement }\end{array}$ & 2 & 16 & HSA faculty \\
\hline Total & 60 & 25 & \\
\hline
\end{tabular}

medical entomology. This gap was to be expected and the syllabus was designed to address this weakness. The first part of module 1 deals with the basics of medical entomology right at the beginning of the course, thus students do not face any difficulty in this respect.

\section{Medical entomology laboratory}

A medical entomology laboratory was established from an existing laboratory and equipped with entomological dissecting microscopes, a $\mathrm{CO}_{2}$ circulating system for restraining insects for observation and other essential instruments required by the students. The existing laboratory was of modest size but functioned well. It was quickly set up with limited resources to start the programme; however, more appropriate, purpose-built laboratories will eventually be needed.

\section{Medical entomology insectary}

A small temporary insectary was established for rearing and processing various insects of medical importance. It was automated for controlled humidity, temperature and daylight periodicity. A number of colonized strains of anopheline, culicine and Aedes mosquito species are being maintained for teaching and research purposes. A team of entomology technicians make routine field collections of anopheline mosquitoes for teaching purposes and also for establishing laboratory colonies that will be helpful for further training and research. This team has locally developed a number of field insect collection instruments and equipment.

\section{MEDVC research centre}

A modest research centre has been established, supplied with computers, library items, WHO test kits, etc. A computer laboratory has also been set up, where postgraduate students can search literature on the Internet. A display corner for entomological journals has been established, where 16 of the most important journals on disease vector biology and control can be accessed. A small laboratory has been set up where WHO insecticide susceptibility test kits, other rapid test kits supplied by WHO 
and facilities for malaria parasitology are available for students. The centre has other facilities, such as photocopying, printing and scanning. To encourage open dialogue between students and teachers on current vector-control issues and promote a culture of continuing education, a programme of weekly talks by eminent vector-control experts is planned.

\section{Discussion}

The key question is why vector-borne diseases continue to cause considerable mortality, morbidity and retardation of socioeconomic development when effective IVM vector-control tools are available along with significant guidance, both regional and global, for their implementation [21,22]. Persistence and increase of vector-borne diseases in the Region may be explained by the number of new natural and man-made vector-breeding sources and increased transmission potential. However, one of the most important factors appears to be the shortage of trained manpower in the field of vector control. In the absence of technical capability, the available vector-control tools are either not used or are used inappropriately. It is important to note that experts in disease vector control, not only in Pakistan but also in other countries, are scarce. Thus, if research is not built into the national programme for vector-borne disease control, the programme may not be successful or may not grow to its full potential. Indigenous research again requires technically trained staff.

In view of the above, the WHO consultations on IVM in 2007 and 2008 put considerable emphasis on capacity strengthening, including infrastructure, training and human resources for IVM $[24,25]$. The 52nd regional committee meeting resolution strongly recommended establishment of and support for a regional course in MEDVC [19].

In Pakistan, no university, institution or research centre provides formal education in the field of medical entomology, especially in disease vector control. The lack of interest in this field is largely due to the fact that the significance and extent of the burden of vector-borne diseases has not been clearly understood and has been underestimated. Moreover, a focus on more lucrative and thus more prestigious curative medicine, rather than on preventive medicine, may also explain the neglect in capacity building in this field.

The greatest hurdle faced in the establishment of this diploma course has been the acute shortage of appropriate faculty in the field of disease vector control. The Regional Office has provided international experts to supplement the local faculty. The other major hurdle was the lack of understanding of the gravity of the situation resulting from this disease burden and thus scarcity of financial resources. The most important requirement for such training was finance for internal and external faculty, field work, entomological laboratories and insectaries. As these facilities did not exist at HSA, modest facilities were developed and at times equipment, materials and facilities were shared with other national institutions.

The first training course is nearing its successful completion; however, sustainability of the course depends upon availability of reasonable technical and financial resources.

It is estimated that each district in Pakistan needs at least two vectorcontrol trained staff. Therefore, to fulfil the immediate national requirement, the MEDVC course has the target of producing at least 300 qualified professionals in the next 5-10 years. Those trained will go into operational disease vector-control programmes in Pakistan. This training programme will effectively respond to the priority need for training of national vector-control staff at federal level and in each district at provincial health departments.

In conclusion, it is expected that well-trained MEDVC postgraduate diploma holders will form the backbone of health services at the district level and be able to ensure sustainable public health services at grass root level through communityempowermentand involvement. The course organization and its academic programme have been successful. In order to make the best of this new public health capacity-building programme, a strong partnership needs to be developed between the Federal Government and the provincial health departments to sustain its implementation, while the support of international partners will be an asset.

\section{References}

1. Guidelines for planning and implementation of malaria vector control at district level. Islamabad, Directorate of Malaria Control, Ministry of Health, 2007.

2. Report on the regional workshop on the urban vector control. Cairo, World Health Organization, Regional Office for the Eastern Mediterranean, 1990 (WHO-EM/VBC/51-E).

3. Geographical description of arthropod-borne diseases and their principal vectors. Geneva, World Health Organization, 1989 (WHO/VBC/89.967).
4. Roosendaal JA. Vector control: methods for use by individuals and communities. Geneva, World Health Organization, 1997.

5. Bednets for all: regional consultation on preparation of a regional strategy on insecticide- impregnated bednets and other materials. Cairo, World Health Organization, Regional Office for the Eastern Mediterranean, 1998 (WHO-EM/VBC/097/E/L).

6. Vector control for malaria and other mosquito-borne diseases: report of a study group. Geneva, World Health Organization, 1995 (WHO Technical Report Series, No. 857). 
7. Rathor HR. The role of vectors in emerging and re-emerging diseases in the Eastern Mediterranean Region. Eastern Mediterranean Health Journal, 1996, 2(1):61-67.

8. Integrated vector management: strategic framework for the Eastern Mediterranean Region 2004-2010. Cairo, World Health Organization, Office for the Eastern Mediterranean, 2004.

9. The world health report 2002 - reducing risks, promoting healthy life. Geneva, World Health Organization, 2003.

10. WaqarS, Tariq WZ. Crimean-Congo haemorrhagic fever(CCHF) in Pakistan. Pakistan Journal of Pathology, 2006, 17(2):74-84.

11. Munir MA, ed. Guidelines for the treatment and prevention of $\mathrm{Cu}$ taneous leishmaniasis in Pakistan. Islamabad, Ministry of Health and World Health Organization, 2002.

12. Brooker $\mathrm{S}$ et al. Leishmaniasis in refugee and local Pakistani populations. Emerging Infectious Diseases, 2004, 10(9):1681-1684.

13. Khan S J, Muneeb S. Cutaneous leishmaniasis in Pakistan. Dermatology Online Journal, 2005, 11(1):4 (http://dermatology-s10. cdlib.org/111/reviews/leishmaniasis3/khan.html, accessed 1 May 2010).

14. Shakila A et al. Geographical distribution of cutaneous leishmaniasis and sand flies in Pakistan. Turkiye Parazitoloji Dergisi, 2006, 30(1):1-6.

15. Chan YC et al. Dengue hemorrhagic fever outbreak in Karachi, Pakistan. Transactions of the Royal Society of Tropical Medicine and Hygiene, 1995, 89:619-620.

16. Siddiqui FJ, Hyder SR, Bhutta ZA. Endemic dengue fever: a seldom recognized hazard for Pakistani children. Journal of Infection in Developing Countries, 2009, 3(4):306-312.
17. Dennis D. Plague in India. British Medical Journal, 1994, 309:893-894.

18. Human plague in 1994. Weekly Epidemiological Record, 1996, 71:165-172.

19. Report of the regional committee for the Eastern Mediterranean, fifty-second session. Cairo, World Health Organization Regional, Office for the Eastern Mediterranean, 2005 (EM) RC52/R6).

20. WHO position statement on integrated vector management. Geneva, World Health Organization, 2008 (WHO/HTM/NTD/ VEW/2008-2)

21. Integrated vector management: regional strategic framework 2003-2006. Cairo, World Health Organization, Regional Office for the Eastern Mediterranean, 2003.

22. Global strategic framework for the integrated vector management. Geneva, World Health Organization, 2004 (WHO/CDS/ CPE/PVC/2004.10).

23. The work of WHO in the Eastern Mediterranean Region: annual report of the regional director 1 January-31 December 2008. Cairo, World Health Organization, Regional Office for the Eastern Mediterranean, 2009.

24. Report of the $\mathrm{WHO}$ consultation on integrated vector management. Geneva, World Health Organization, 2007 (WHO/COS/ NTOWEM/2007.1).

25. Report on the WHO consultation on development of a global action plan for integrated vector management 1-3 December 2008. Geneva, World Health Organization, 2009 (WHO/HTM/ NTOWEM/2009.1). 